\title{
Welfare of cattle kept in intensive silvopastoral systems: A case report
}

\section{Ariel Marcel Tarazona Morales ${ }^{1 *}$, Maria Camila Ceballos ${ }^{2,3}$, Guillermo Correa Londoño ${ }^{4}$, César Augusto Cuartas Cardona ${ }^{5}$, Juan Fernando Naranjo Ramírez ${ }^{6}$, Mateus José Rodrigues Paranhos da Costa ${ }^{2,7}$}

\footnotetext{
${ }^{1}$ Universidad Nacional de Colombia, Facultad de Ciencias Agrarias, Departamento de Producción Animal, Medellín, Colombia.

${ }^{2}$ Grupo de Estudos e Pesquisas em Etologia e Ecologia Animal, Jaboticabal, SP, Brazil.

${ }^{3}$ Universidade Estadual Paulista, Faculdade de Ciências Agrárias e Veterinárias, Programa de Pós-graduação em Zootecnia, Jaboticabal, SP, Brazil.

${ }^{4}$ Universidad Nacional de Colombia, Facultad de Ciencias Agrarias, Departamento de Ciencias Agronómicas, Medellín, Colombia.

${ }^{5}$ Grupo de Investigación en Producción, Desarrollo y Transformación Agropecuaria, Medellín, Colombia.

${ }^{6}$ Universidad CES, Facultad de Medicina Veterinaria y Zootecnia, Grupo INCA-CES, Medellín, Colombia.

${ }^{7}$ Universidade Estadual Paulista, Faculdade de Ciências Agrárias e Veterinárias, Departamento de Zootecnia, Jaboticabal, SP, Brazil.
}

ABSTRACT - The objective of this research was to evaluate the effect of three different intensive silvopastoral systems (ISPS) on cattle animal welfare (AW) in Colombia. The three ISPS differed in area, plant composition, and grazing periods as follows: ISPS1 - low plant diversity in paddocks of $1200 \mathrm{~m}^{2}$, with grazing period of $24 \mathrm{~h}$; ISPS2 - middle plant diversity in paddocks of $600 \mathrm{~m}^{2}$, with grazing period of $12 \mathrm{~h}$; and ISPS3 - high plant diversity in paddocks of $600 \mathrm{~m}^{2}$, with grazing period of $24 \mathrm{~h}$. Animal welfare was assessed using a wide range of criteria, which were integrated using L-spline functions and Choquet integrals to generate overall values. It was found that AW was good in all ISPS; the highest scoring criteria was for food and water, with 99, 97, and 100 points from a maximum of 100 for ISPSs 1, 2, and 3, respectively. Comfort showed values of 100 for all three systems, but good health was the most problematic criteria of the AW features with scores of 25 , 40 , and 36 for ISPSs 1, 2, and 3, respectively. All three ISPS showed excellent scores for appropriate behavior (82, 88, and 89). The welfare problems shown here were not specific to the individual ISPS, but were common to all livestock systems in the region. Despite the differences in diversity of plants, size of paddocks, and grazing period among the three ISPSs tested, all of them provide cattle with sufficient resources and a diverse environment, ensuring a good state of welfare to them.

Key Words: animal emotion, animal welfare, appropriate behavior, livestock, sustainability

\section{Introduction}

Animal production systems have focused on the quantity and quality of the products while giving insufficient attention to sustainability, including animal welfare (AW) and moral standards. There is growing concern surrounding the impact of animal production upon the environment, economy, and food security (Steinfeld et al., 2006). Societal pressure, combined with scientific evidence demonstrating the relationships between AW and competitiveness, biodiversity, and public health, has led to the acceptance of

Received: September 7, 2016

Accepted: February 13, 2017

*Corresponding author: amtarazonam@unal.edu.co

http://dx.doi.org/10.1590/S1806-92902017000600002

How to cite: Tarazona Morales, A. M.; Ceballos, M. C.; Correa Londoño, G.; Cuartas Cardona, C. A.; Naranjo Ramírez, J. F. and Paranhos da Costa, M. J. R. 2017. Welfare of cattle kept in intensive silvopastoral systems: A case report. Revista Brasileira de Zootecnia 46(6):478-488.

Copyright (c) 2017 Sociedade Brasileira de Zootecnia. This is an Open Access article distributed under the terms of the Creative Commons Attribution License (http://creativecommons.org/licenses/by/4.0/), which permits unrestricted use, distribution, and reproduction in any medium, provided the original work is properly cited.
AW as part of sustainability criteria (Broom, 2010). Animal welfare describes the quality of life of an animal and can be defined as "the state of an individual in relation to its attempts to cope with its environment" (Broom, 1986). The science of AW seeks evidence of an animal's degree of adaptation and coping with environmental conditions. The evaluation of AW refers to biological measures of the animal as an individual at a given time on a scale ranging from very poor to very good and can be measured quantitatively using many criteria (Broom, 2011).

Cattle production systems vary widely in Latin America. In tropical countries such as Colombia, most cattle production is based on extensive systems. This has sometimes led to desertification with low levels of production and reproduction efficiency (Steinfeld et al., 2006). Introducing sustainable production systems, including intensive silvopastoral systems (ISPS), has been a successful alternative (Murgueitio et al., 2011; Broom et al., 2013.). An ISPS is a form of agroforestry, integrating high densities of fodder shrubs $(5,000$ to more than 30,000/ha) such as Leucaena leucocephala or Tithonia diversifolia in association with improved pasture and timber, fruit, or palm trees (50 to more than 500 trees/ha) 
(Tarazona et al., 2013). This kind of system is becoming generally accepted by cattle producers because of their economic, environmental, and social benefits, as well as its potential positive effects on animal welfare. Mancera and Galindo (2011) reported that animals in silvopastoral systems were calmer and showed less avoidance of humans than animals on conventional pasture. The objective of this study was to evaluate the status of AW in three different types of ISPS in three regions of Colombia.

\section{Material and Methods}

All procedures performed in this study were consistent with the Colombian legislation on animal welfare, meeting the protocol requirements of animal research of the Ethics Committee in Animal Use (Certified CEMED 041) in Medellín, Colombia, and we did not interfere with the animals in the study, since data collection was carried on during usual handling routine for cattle handling procedures. We evaluated three types of ISPS, in which the animals were free to graze the pasture and browse the shrubs, within pre-defined areas (with electric fencing) for periods of 12 or $24 \mathrm{~h}$, having permanent access to water and mineral supplementation.

The ISPSs were located on private farms, differing in area, plant composition, and grazing period (Figure 1). The ISPS1, located in Bugalagrande, Valle del Cauca $\left(4^{\circ} 13^{\prime} 17.46^{\prime \prime} \mathrm{N}\right.$, $76^{\circ} 08^{\prime} 53.68^{\prime \prime} \mathrm{W}$ ), in a sub humid tropical forest ecosystem (Holdridge, 1987), has an altitude of $960 \mathrm{~m}$, an average rainfall of $1050 \mathrm{~mm} /$ year, $75 \%$ relative humidity, and an average temperature of $24{ }^{\circ} \mathrm{C}$. This ISPS had low plant diversity, with only three species: Leucaena leucocephala, as shrub to browse at a rate of more than 10,000 shrubs/ha, and the grasses Cynodon plectostachyus and Megathyrsus maximus. In this system, groups of 20 Lucerna cattle (Criollo breed of Bos taurus cattle) ranging from 11 to 14 months with an average weight of $289 \mathrm{~kg}$ grazed in areas of $1,200 \mathrm{~m}^{2}$ with rotation every $24 \mathrm{~h}$, conducted between 06:00 and 08:00 h. The ISPS2 is located in Piedras, Tolima $\left(04^{\circ} 29^{\prime} 06.7^{\prime \prime} \mathrm{N}, 74^{\circ} 59^{\prime} 15.4^{\prime \prime} \mathrm{W}\right)$, in a tropical dry forest ecosystem (Holdridge, 1987), with $605 \mathrm{~m}$ altitude, an average rainfall of $1350 \mathrm{~mm} / \mathrm{year}, 71 \%$ relative humidity, and an average temperature of $26{ }^{\circ} \mathrm{C}$. This ISPS had more diverse plant community, with five species: Leucaena leucocephala, as shrubs for browsing (greater than 10,000 shrubs/ha), and Cynodon plectostachyus associated with Azadirachta indica, Albizia guachapele, and Tectona grandis as timber; in this system, there were groups of 20 zebu (Bos indicus) males, 24 months of age with an average weight of $357 \mathrm{~kg}$, grazed in areas of $600 \mathrm{~m}^{2}$ with rotation every $12 \mathrm{~h}$, conducted at 06.00 and $18.00 \mathrm{~h}$. The ISPS3 is located in San Onofre, Sucre (09 $\left.51^{\prime} 24.86^{\prime \prime} \mathrm{N}, 75^{\circ} 26^{\prime} 02.44^{\prime \prime} \mathrm{W}\right)$, in a tropical dry forest ecosystem (Holdridge, 1987), with 134 m altitude, an average rainfall of $1,000 \mathrm{~mm} /$ year, $83.5 \%$ relative humidity, and an average temperature of $27.1^{\circ} \mathrm{C}$. This ISPS had higher plant diversity, with eight species: Leucaena leucocephala and Guazuma ulmifolia, as shrubs for browsing (greater than 8000 shrubs/ha), Cynodon plectostachyus and Megathyrsus maximus as grasses and Tabebuia rosea, Pachira quinata, Cordia gerascanthus, and Acacia mangium as timber; in this system, groups of 16 crossbred zebu males, ranging from 10 to 12 months of age with an average weight of $252 \mathrm{~kg}$, grazed in areas of $600 \mathrm{~m}^{2}$ with rotation every $24 \mathrm{~h}$, conducted at 10.00 and $11.00 \mathrm{~h}$.

An adaptation of the Welfare Quality protocol (Welfare Quality $^{\circledR}$, 2009) was used to assess the welfare of cattle kept under the three types of ISPS studied. Six days were necessary to complete the assessment in each system and it was done by using animal and environmental indicators. The AW indicators were grouped in four major criteria (food and water provision, comfort, health, and behaviour) and, for each major criterion, a range of sub-criteria was defined, as follows:

Food and water provision: the food supply was determined by measuring grazing pressure, considering the available biomass of food, animal weight and density, and the availability of mineral supplementation (Forkman and Keeling, 2009). To estimate the available biomass on each ISPS, we used the comparative yield technique (Haydock and Shaw 1975). Then, the grazing pressure was calculated by the ratio between dry matter requirements of livestock and the quantity of forage available in the paddock at a specific time of grazing (Mott, 1960). The body condition was scored on a scale of 1 to 9 . The quality and quantity of supply of water (L/animal), the size (area and volume) of the water points, the number of drinkers, the number of animals per water point, and the cleanliness of the water points were all evaluated to be sufficient (Forkman and Keeling, 2009). Signs of dehydration were assessed in the animals by direct observation based on skin elasticity on thorax and enophthalmia.

Comfort: comfort associated with resting (CR) was evaluated and scored according to the methods described by Cozzi et al. (2010), including an evaluation of the cattle body dirtiness, assessed in the right side of the animal body, excluding extremities and head. Thermal comfort (TC) was assessed by measuring and recording skin temperature on the back and abdomen of the animal using an Extech DR-42 510 IR laser thermometer. The air temperature and relative humidity were recorded in each ISPS during all AW 
assessment days (Table 1). Respiratory rate was evaluated by observing the abdomen posterior to the last rib. Ease of movement (EM) was evaluated by the space available to the animals (animals/area).

Health: presence or absence of injuries was assessed by recording any difficulty in walking, when animals were in motion, by recording when limping was present, regardless of its intensity. Integument alterations were also recorded, including the number of hairless patches and lesions or swellings (Busato et al., 2000). Disease was assessed by clinical observation of the number of coughs registered in
Table 1 - Means of air temperature (AT) and relative humidity (RH) during the assessment period of animal welfare indicators in the three intensive silvopastoral systems evaluated

\begin{tabular}{|c|c|c|c|c|c|c|}
\hline & \multicolumn{2}{|c|}{ ISPS1 } & \multicolumn{2}{|c|}{ ISPS2 } & \multicolumn{2}{|c|}{ ISPS3 } \\
\hline & $\begin{array}{l}\mathrm{AT} \\
\left({ }^{\circ} \mathrm{C}\right)\end{array}$ & $\begin{array}{l}\text { RH } \\
(\%)\end{array}$ & $\begin{array}{l}\text { AT } \\
\left({ }^{\circ} \mathrm{C}\right)\end{array}$ & $\begin{array}{l}\text { RH } \\
(\%)\end{array}$ & $\begin{array}{c}\text { AT } \\
\left({ }^{\circ} \mathrm{C}\right)\end{array}$ & $\begin{array}{l}\mathrm{RH} \\
(\%)\end{array}$ \\
\hline $24 \mathrm{~h}$ & 23.4 & 73.9 & 26.6 & 68.5 & 27.7 & 83.0 \\
\hline $06: 00-18: 00 \mathrm{~h}$ & 28.5 & 60.1 & 30.9 & 60.4 & 31.4 & 71.2 \\
\hline $10: 00-14: 00 \mathrm{~h}$ & 32.7 & 47.9 & 34.1 & 53.1 & 34.3 & 62.0 \\
\hline
\end{tabular}

ISPS - intensive silvopastoral system.

ISPS1: low plant diversity; ISPS2: middle plant diversity; ISPS 3: high plant diversity, considering three periods: $24 \mathrm{~h}$ (full day), 06:00 to 18:00 h (diurnal), and from 10:00 to $14: 00 \mathrm{~h}$ (the hottest period of the day).
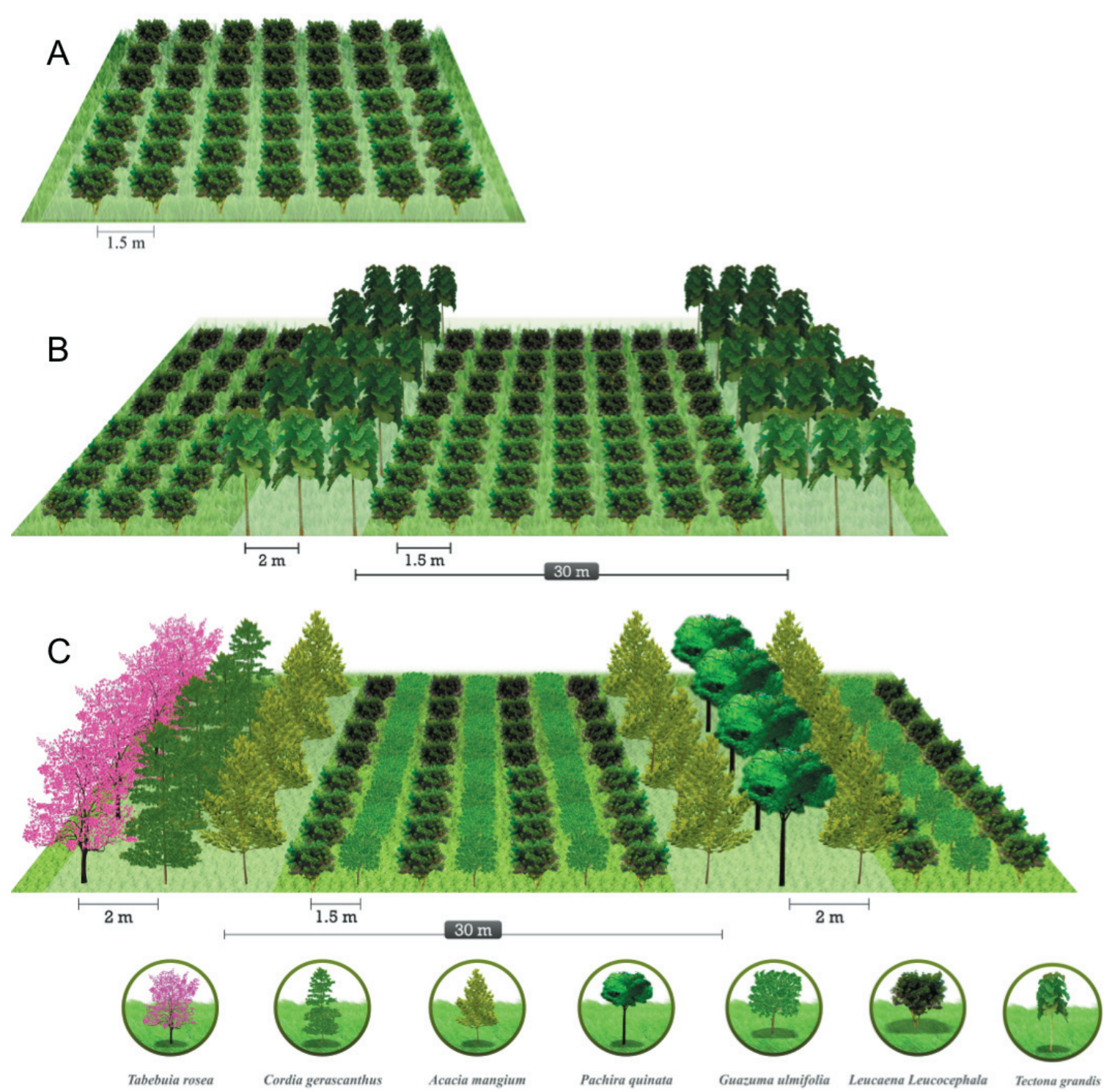

A: ISPS1 - low plant diversity (Leucaena leucocephala for browsing and Cynodon plectostachyus and Megathyrsus maximus for grazing); B: ISPS2 - middle plant diversity (Leucaena leucocephala for browsing, Cynodon plectostachyus for grazing associated with Azadirachta indica, Albizia guachapele, and Tectona grandis as timber); and C: ISPS3 - high plant diversity (Leucaena leucocephala and Guazuma ulmifolia for browsing, Cynodon plectostachyus and Megathyrsus maximus for grazing and Tabebuia rosea, Pachira quinata, Cordia gerascanthus, and Acacia mangium as timber).

Figure 1 - Illustration of the plant arrangements of each intensive silvopastoral system (ISPS) evaluated. 
120 min and the presence of nasal and ocular discharges; breathing difficulties (defined as deep and overtly difficult or laboured breathing accompanied by sound); and the presence or absence of diarrhoea. A count of the total number of flies and ticks on the back of the animal was also recorded. Pain was assessed by questions posed to the farmers on how to perform surgical procedures, if they use analgesics and anaesthetics, and also the type of procedure used in castrating and dehorning (Forkman and Keeling, 2009).

Behaviour: agonistic and cohesive behaviours (Forkman and Keeling, 2009), plus grazing, browsing, grooming, scratching, and leaning against the shrubs behavioural categories were observed. Human-animal relationship was measured as avoidance distance (Waiblinger et al., 2006). The emotional state of the animals was assessed by Qualitative Behaviour Assessment (QBA) as described by Rousing and
Wemelsfelder (2006), which is a method that has been employed to evaluate animal welfare (Wemelsfelder et al., 2000). The QBA was sampled by using an analogue scale that includes 19 terms (active, relaxed, apathetic, calm, content, scared, enjoying, indifferent, frustrated, friendly, annoyed, positively occupied, curious, irritable, nervous, attentive, sociable, happy, and distressed).

The evaluation of each major criterion to know the cattle welfare in each ISPS was based on a hierarchical structure, which allowed the sub-criteria to be grouped into indices. The score for each sub-criterion was derived from different analytical methods depending on the characteristic and its component indicators, as follows:

Indicators such as water supply, surgical procedures, castration, dehorning, and hot branding were assessed from records at the farm level and expressed in a limited number

Table 2 - Calculations used for the integration of the qualifications within each welfare indicator of cattle in silvopastoral systems

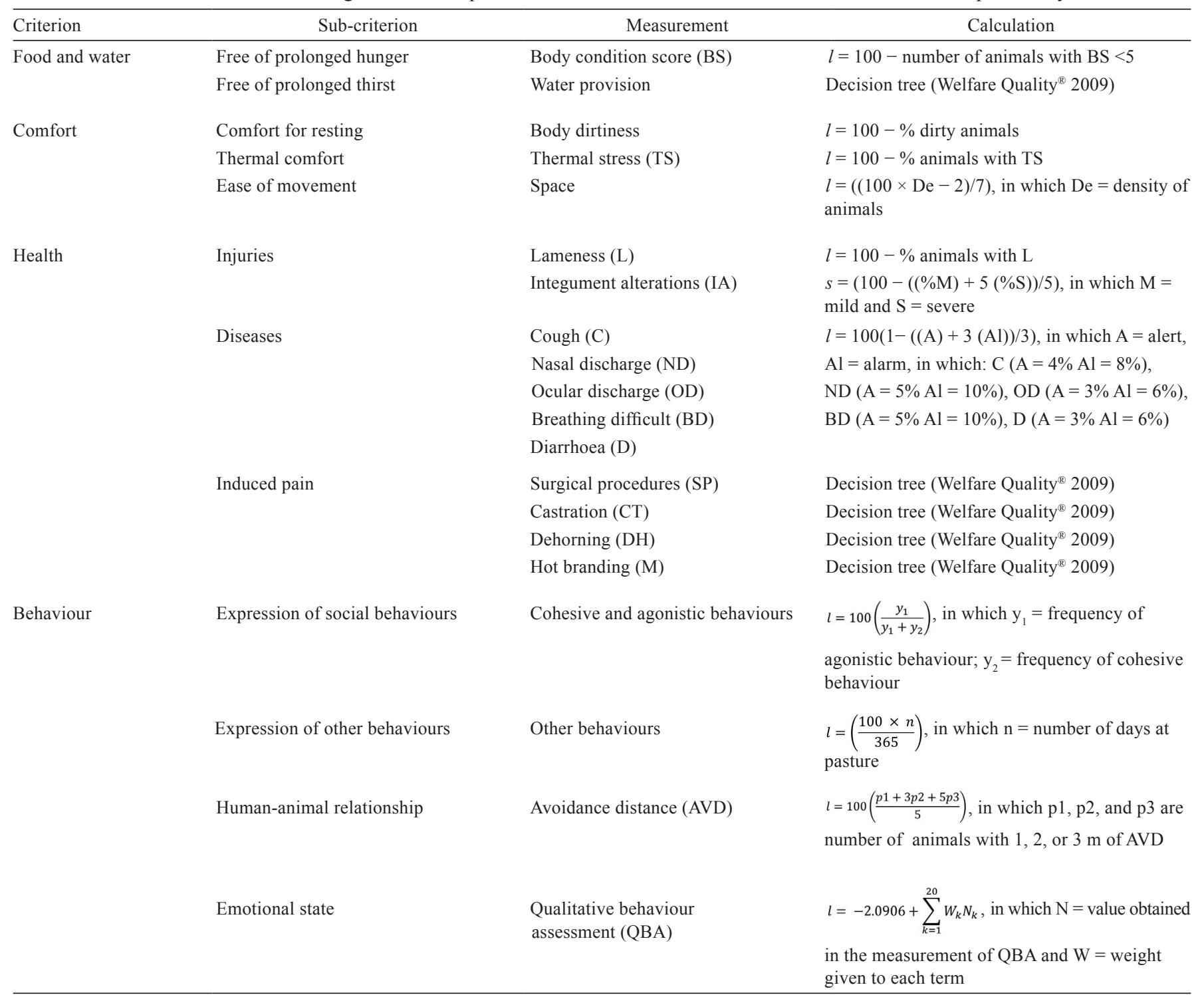


of categories. Decision trees were implemented; depending upon a series of "yes or no questions", the end result of each branch corresponded to a score of 0 to 100 (Welfare Quality $\left.^{\circledR}, 2009\right)$. Body condition, comfort associated with resting, thermal comfort, and ease of movement were evaluated from variables rated individually on a severity scale, followed by calculation of the proportion of animals with the corresponding problem. In this case, a weighted sum was obtained by assigning a weight to each level of severity followed by calculation of the index (Table 2). The index was then converted into a score using an L-spline function, which allows data interpolation in several dimensions, minimizing the variability generated by differences in the data. Measures used to assess the space, integument alterations, and absence of disease yielded data expressed as different measures relative to an alarm threshold (Table 2), which represented a threshold of acceptance or unacceptance. We calculated the number of alarms and warnings, upon which a weighted sum, which had been transformed into a score using an L-spline function, was based (Table 2). Emotional state considered the frequency of the behaviours described above and the ability to graze freely; calculations resulted in a proportion of behaviours transformed into an index using an L-spline function (Table 2).

The following 19 terms were used to describe the emotional state of the animal relating to QBA. Because each term carried a different weight, the result was calculated by multiplying the visual record of the assessors by the corresponding weights for each term, which then yielded a weighted sum (Table 2) taking into account the following specific weights for each term: active (0.00434), relaxed (0.00784), apathetic $(-0.0102219)$, calm $(0.00120)$, content $(0.01015)$, scared $(-0.004064)$, enjoying $(0.01040)$, indifferent $(-0.009991)$, frustrated $(-0.0115037)$, friendly (0.00976), annoyed (-0.00980), positively occupied $(0.00979)$, curious $(0.00560)$, irritable $(-0.002443)$, nervous $(-0.001544)$, attentive $(0.00403)$, sociable $(0.00838)$, happy $(0.0106)$ and distressed $(-0.009564)$.

After calculating the indices for each sub-criterion, they were integrated for each criterion (Table 2). Since the criteria weigh differently for the final value of AW, measurement blocks were compiled using Choquet integrals whose reference parameters ( $\mu$ values) were: $\mu_{1} 0.08 ; \mu_{2} 0.26$; $\mu_{3} 0.22 ; \mu_{34} 0.26 ; \mu_{35} 0.36 ; \mu_{4} 0.18 ; \mu_{45} 0.30 ; \mu_{5} 0.18 ; \mu_{6} 0.09$; $\mu_{67} 0.43 ; \mu_{68} 0.24 ; \mu_{7} 0.23 ; \mu_{78} 0.23 ; \mu_{8} 0.13 ; \mu_{9} 0.06 ; \mu_{910} 0.09$; $\mu_{911} 0.09 ; \mu_{912} 0.17 ; \mu_{91011} 0.41 ; \mu_{91012} 0.52 ; \mu_{91112} 0.55 ; \mu_{10}$ $0.03 ; \mu_{1011} 0.14 ; \mu_{1012} 0.18 ; \mu_{10112} 0.51 ; \mu_{11} 0.09 ; \mu_{1112} 0.27$; and $\mu_{12}$ 0.15. The subscript numbers indicate the criterion or the interaction between the criteria within the same principle (Forkman and Keeling, 2009). The rating of the principles was presented on a categorical scale considering the following values: excellent (80-100), good (60-80), fair (20-60), and not qualified (0-20). Finally, AW level was stated for each principle and given an overall value for each production system: excellent (E), if more than 55 points in all principles and if at least two of them have more than 80 points; good $(\mathrm{G})$, if more than 20 points in all principles and more than 55 in two of them; and acceptable (A), if more than 10 points in all principles and more than 20 in two of them.

\section{Results}

The AW indicators were similar among the three ISPS for food, comfort, and behaviour and were at a satisfactory standard. However, some of the indicators for health were low (Table 3).

It was found that the food needs of the animals were met without evidence of malnutrition or dehydration in any of the three ISPS. Food supply was sufficient and allowed the animals to select their diets, resulting in BS between 6.5 and 7.0, considered very good for grazing animals without supplementation with concentrate feed. In relation to comfort, it was found that cleanliness was optimal for all animals in the three ISPS. There was no evidence of thermal stress and respiratory rates were normal. The space provided was 37.5 to $60 \mathrm{~m}^{2} /$ animal. In relation to health, the animals from all ISPS faced problems with induced pain, resulting from castration, dehorning, and hot branding practices, which were carried out without using anaesthesia or analgesia. Signs of diseases and injuries were also observed (Table 3). For the criterion of appropriate behaviour, it was found that the three ISPS allowed the animals to express social and other behaviours and we did not observe any evidence of competitive situations that led to intense agonistic behaviours; thus, the three ISPS obtained the highest score (100 points) for this sub-criterion. There was a good human-animal relationship, as indicated by the short animal avoidance distance and the good scores for emotional status of most animals in all ISPS (Table 3).

The integrated indices of the indicators showed that all ISPS met satisfactory conditions for most of the subcriteria, among them: free of prolonged hunger and thirst, comfort for resting, thermal comfort, easy of movement, expressions of social and other behaviours, human-animal relationship, and emotional status (Table 4). The ISPS1 had a lower rate within the injuries sub-criterion. The disease sub-criterion was highly variable among the assessed ISPS, with scores of 100, 81, and 54.6 for ISPS 1, 2, and 3, 
respectively. The sub-criterion with the fewest points was induced pain, which had score of 0 for all ISPS.

According to the classification system used, all systems were classified as good animal welfare (Table 5).

\section{Discussion}

Some previous studies, carried out in different scenarios, have used the Welfare Quality protocol to assess welfare of cattle and other farm species (Dalmau et al., 2009; Temple et al., 2011; Kirchner et al., 2014). Nevertheless, to our knowledge, this is the first scientific study reporting in detail the cattle welfare status in different ISPS using this methodology. It was found that the welfare was good, except for health problems common to the region, in all three ISPS evaluated. Food and water had high scores of 99, 100, and 97 for ISPS 1, 2, and 3, respectively. The various measures of comfort had values of 100 for all three systems. Health had the lowest scores with 40, 36, and 25, for ISPS 1, 2, and 3, respectively. The scores of behaviour indicators were excellent in all systems: 88,89 , and 82 for ISPS 1,2 , and 3 , respectively.

The contribution of food and water variables on the welfare was high in all ISPS evaluated (98.8) and all animals had a body condition score between 6.5 and 7 . This is a good indicator of AW, because it shows the degree to which the animals' food needs are being met, reflecting body fat content and body reserves and is related to the maintenance of health. The grazing pressure was between 6.9 and $9.2 \mathrm{~kg}$ dry matter (DM)/100 kg body weight, which

Table 3 - Values obtained from the qualifications within each welfare indicator of cattle in silvopastoral systems

\begin{tabular}{|c|c|c|c|c|c|}
\hline Criterion & Sub-criterion & Measurement & ISPS1 & ISPS2 & ISPS3 \\
\hline \multirow[t]{2}{*}{ Food and water } & $\begin{array}{l}\text { Free of prolonged } \\
\text { hunger and thirst }\end{array}$ & Food offer (kg DM/100 kg live weight) & 9.24 & 8.46 & 6.9 \\
\hline & & Body condition score ( 0 to 9 ) & 6.7 & 7.0 & 6.5 \\
\hline Comfort & $\begin{array}{l}\text { Ease of movement } \\
\text { Thermal comfort }\end{array}$ & $\begin{array}{l}\text { Space } \mathrm{m}^{2} / \text { animal } \\
\text { Breathing rate } \\
\text { Skin temperature (back) }\left({ }^{\circ} \mathrm{C}\right) \\
\text { Skin temperature (abdomen) }\left({ }^{\circ} \mathrm{C}\right)\end{array}$ & $\begin{array}{c}60 \\
48.6 \\
37.3 \\
35.5\end{array}$ & $\begin{array}{c}60 \\
72.6 \\
37.5 \\
35.8\end{array}$ & $\begin{array}{l}37.5 \\
55.0 \\
40.0 \\
36.0\end{array}$ \\
\hline
\end{tabular}

DM - dry matter; ISPS - intensive silvopastoral system; QBA - qualitative behaviour assessment.

ISPS1: low plant diversity; ISPS2: middle plant diversity; ISPS3: high plant diversity.

Table 4 - Values obtained from the integration of indicators for animal welfare criteria evaluated in three intensive silvopastoral systems in Colombia

\begin{tabular}{|c|c|c|c|c|}
\hline Criterion & Sub-criterion & ISPS1 & ISPS2 & ISPS3 \\
\hline \multirow[t]{2}{*}{ Food and water } & Free of prolonged hunger & 98.8 & 98.8 & 98.8 \\
\hline & Free of prolonged thirst & 100 & 100 & 80 \\
\hline \multirow[t]{4}{*}{ Comfort } & Comfort for resting & 99.9 & 99.9 & 99.9 \\
\hline & Thermal comfort & 100 & 100 & 100 \\
\hline & Lameness & 99.9 & 99.9 & 99.9 \\
\hline & Space & 100 & 100 & 100 \\
\hline \multirow[t]{3}{*}{ Health } & Injuries & 76.4 & 91.2 & 61.4 \\
\hline & Diseases & 100 & 81.0 & 54.6 \\
\hline & Induced pain & 0 & 0 & 0 \\
\hline \multirow[t]{4}{*}{ Behaviour } & Expression of social behaviours & 100 & 100 & 100 \\
\hline & Expression of other behaviours & 100 & 100 & 100 \\
\hline & Human-animal relationship & 94.97 & 96.58 & 98.18 \\
\hline & Emotional state & 83 & 84 & 71 \\
\hline
\end{tabular}

ISPS - intensive silvopastoral system.

ISPS1: low plant diversity; ISPS2: middle plant diversity; ISPS3: high plant diversity. 
Table 5 - Estimation of integrated values for four animal welfare principles and final value of welfare status in three intensive silvopastoral systems evaluated in Colombia

\begin{tabular}{lccc}
\hline Principle & ISPS1 & ISPS2 & ISPS3 \\
\hline Food and water & 99 & 100 & 97 \\
Comfort & 100 & 100 & 100 \\
Health & 40 & 36 & 25 \\
Behaviour & 88 & 89 & 82 \\
Animal welfare status & Excellent & Excellent & Excellent \\
\hline
\end{tabular}

ISPS - intensive silvopastoral system.

ISPS1: low plant diversity; ISPS2: middle plant diversity; ISPS3: high plant diversity

shows an adequate supply of food necessary to meet the nutritional needs. The forage available for consumption is an advantage in the ISPS and it can produce between 3.5 and $5.0 \mathrm{t} \mathrm{DM} /$ ha with degradability greater than $63 \%$ (BarrosRodríguez et al., 2012) and animals can obtain more than $75 \%$ of the available biomass (Bacab-Pérez and SolorioSánchez, 2011). The composition of the diet influences how the animal meets its needs. Approximately $12.8 \mathrm{~g}$ $\mathrm{N} / \mathrm{kg} \mathrm{DM}$ of the diet of the animal is required to ensure proper functioning of the rumen and forage-based diets with low $\mathrm{N}$ (like most tropical grasses) are not sufficient and, therefore, require $\mathrm{N}$ supplementation to compensate this deficiency. All ISPS had a forage composition that included L. leucocephala, which contained between 25 and $35 \mathrm{~g} \mathrm{~N} / \mathrm{kg}$ DM (Barros-Rodríguez et al., 2012), and the feed mixture contained between 24 and $28 \mathrm{~g} \mathrm{~N} / \mathrm{kg}$ DM. Leucaena is considered a protein supplement with more than $16 \mathrm{~g} \mathrm{~N} / \mathrm{kg}$ DM (CSIRO, 2007).

Absence of thirst had scores of 100, 100, and 80 for ISPS 1, 2, and 3, respectively, and no clinical signs of dehydration were observed. Despite the importance of water in $\mathrm{AW}$, there are few studies on water intake in grazing beef cattle. This is primarily due to the fact that most work has been carried out in confinement systems and secondly, water, as a resource, has been considered readily available at a low cost for production systems (Brew et al., 2011). However, efficient water use is currently a subject of environmental concern, especially in areas where water is scarce. Water intake is related to DM intake and $10 \mathrm{~L} /$ water $/ \mathrm{kg}$ of DM consumed have been suggested for Bos indicus (CSIRO, 2007). Fresh forage consumed by the animals in the ISPS contains 75 to $80 \%$ water; thus, each $\mathrm{kg}$ of DM consumed by the animal contains about $7.85 \mathrm{~L}$ of the water required by the animals. The microclimate of the ISPS promotes water retention in the system; relative humidity can be up to $14 \%$ higher, since the loss of water by evaporation can be $1.5 \mathrm{~mm} /$ day lower when compared with a pasture without trees (Rueda et al., 2011).
It is known that lying is a high priority behaviour and cattle primarily rest and ruminate while lying (Munksgaard and Simonsen, 1996). In this study, it was observed that ruminating and resting areas are not fixed because the animals occupy a different area every day within the rotational management system. In spite of this, the results showed that animals in the ISPS have enough space to move freely and voluntarily choose resting areas $\left(60 \mathrm{~m}^{2} /\right.$ animal in ISPS 1 and ISPS 2 and $37.5 \mathrm{~m}^{2} /$ animal in ISPS3). The comfort indicator around resting in all the ISPS was 99.9, which indicates a favourable environment for resting.

As regards thermal comfort, heat stress is one of the main factors negatively influencing production in tropical livestock systems. As reported by Blackshaw and Blackshaw (1994) in a review paper, the heat threshold for cattle is $30{ }^{\circ} \mathrm{C}$ with relative humidity below $80 \%$, and $27^{\circ} \mathrm{C}$ with a relative humidity close to $80 \%$. Temperatures above these thresholds would have implications for the welfare and health of the animal and therefore affect productive performance (Gaughan et al., 2009). There is evidence that shrubs present in ISPS affect the microclimate of the systems, favouring the avoidance of heat stress, as described by Ceballos et al. (2011). These authors suggested that the lower plant stratum in the system favours the processes of heat exchange between the animal and the system, allowing heat dissipation and promoting thermal comfort, possibly because the vegetation retains more moisture and provides lower temperatures than the top tier. Temperature within ISPS is significantly reduced (differences up to $13{ }^{\circ} \mathrm{C}$ between the maximum and minimum), while relative humidity is increased (between 10 and $20 \%$ ). This could, theoretically, be a disadvantage to the animal in terms of heat loss via evaporation of sweat, but it depends on the moisture content in the air, being critical when the air reaches saturation. We did not find any study addressing this subject on ISPS and further studies are required. In this study, the thermal comfort index for the three ISPS was 100, indicating the absence of heat stress. This result is important because it affects the mechanisms of temperature regulation in cattle. Similar results were found by Sousa et al. (2007), who evaluated a silvopastoral system in Brazil and reported that it was 3 and $4{ }^{\circ} \mathrm{C}$ cooler in the shade, resulting in improved production indicators. Moreover, Sousa et al. (2010) indicated that the microclimatic conditions in silvopastoral system favouring thermal comfort increased feed intake. Respiratory rates were within normal ranges (between 48.6 and 72.6/min).

In ISPS, animals have no individual movement restriction because grazing occurs in groups with sufficient area to maintain individual voluntary distance with other 
animals; maintaining a proper social distance between animals reduces the risk of social stress (Paranhos da Costa and Silva, 2007). In this study, the three ISPS achieved a score of 100 for ease of movement. This result suggests that animals in ISPS have sufficient space to move freely and shrub density in the system does not impede movement, unlike confinement systems where animals can have serious welfare problems when allotted in less than $2 \mathrm{~m}^{2}$ (Fisher et al., 1997). In the ISPS, this indicator showed the highest score, since it is allowed between 10 and 20 times the minimum required space per animal. Moreover, there was no competition for shade, once this was sufficient for all animals at all times.

In the three ISPS evaluated in this study, there was a score of 99.9 in the three cases for the cleanliness indicator. This has positive implications for welfare because, as reported by Leach et al. (2009), cleanliness reflects the quality of animal care and housing and is related to health issues such as dermatitis, mastitis, and lameness. Due to the daily rotation of grazing areas in the ISPS, the risk of lying in areas contaminated with faeces or urine is drastically reduced and the vegetative cover prevents the accumulation of mud and water; hence, the animals easily remain clean. The results are also explained by the possibility that repeated contact with shrubs scratches against the animals, preventing formation of plaques and dirt.

The ISPS2 scored excellent (91.2), while ISPS1 (76.4) and ISPS3 (61.4) were good, regarding absence of injuries. Injuries have been evaluated in housing systems where most of integument alterations are due to repeated collisions with building infrastructure, equipment, or other animals. Such injuries are common in the extremities, neck, hips, and flank (Busato et al., 2000). In all the ISPS, animals spend most of their time in pastoral areas. There is no evidence suggesting that shrubs represent a potential risk of collision or injury. The results of ISPS1 and ISPS3 could be due to management problems in pens, during transport, or as a consequence of previous parasitism, which were not evaluated here, but could constitute common welfare problems associated with all cattle production systems in the tropics.

Lameness was absent in all of the ISPS. In the context of cattle welfare assessment, lesion in the integument (skin, hair, hooves, and horns) has substantial importance and can indicate infrastructure problems regarding animal management (Schulze et al., 2009). It is possible that soil type (Cook and Nordlund, 2009) and poor access to grazing areas (Dippel et al., 2009) are associated with lameness. In
ISPS, animals are constantly grazing and soil characteristics can reduce this risk, because the vegetation generates softer ground and prevents flooding, reducing the amount of moisture on the ground.

Both ISPS1 (100) and ISPS2 (81) had an excellent level of welfare associated with the absence of disease, while ISPS3 had a good level (54.6); this decrease, when compared with the other two systems, was explained by the presence of coughing in some animals, possibly due to rainy weather during the sampling period. All three systems showed low levels in the total number of ectoparasites (flies/ticks); averages were 1/6 for ISPS1, 9/0 for ISPS2, and $0 / 5$ for ISPS3. It has been shown that ISPS contribute to the reduction of parasites and disease vectors (Giraldo et al., 2011), while unwooded, open grazing systems favour the development of parasitic organisms. Giraldo et al. (2011) found that ISPS exhibit significant natural regulation of horn flies (Haematobia irritans), reporting the presence of different groups of organisms associated with manure peat degradation that are involved in the biological control of flies.

The score of induced pain for all three systems was 0 due to the absence of anaesthesia and analgesia during procedures such as castration, dehorning, and hot branding. These practices are common in almost all beef production systems in Colombia and the rest of Latin America (Mota et al., 2016); therefore, it is not inherent to ISPS, but a result of widespread poor management practices.

Behaviour measures have become an integral part of AW assessment. Social stress due to faulty production system management can negatively influence the quality of meat, weight gain (Stookey and Gonyou, 1994), and reproduction (Dobson et al., 2001) and inadequate humananimal relationships can also adversely affect the farm animal productivity (Hemsworth and Coleman, 2011).

With a score of 100 for expressing social behaviour, good welfare was found in all three ISPS; agonistic behaviours were not a problem. This is a very good result, since cattle are social animals and the company of their own species is vital (Paranhos da Costa and Silva, 2007). The ISPS evaluated in this study provided enough resources to avoid competition, preventing agonistic behaviour. Notably, the animals expressed cohesive behaviours. There was no evidence of welfare problems caused by social hierarchies or agonistic behaviours, possibly because the groups were small enough to allow social structure to be maintained.

The three assessed ISPS allowed the expression of other behaviours and, thus, have the highest welfare qualification (100). Grazing behaviour is important for 
animals (Manteca et al., 2008); in the ISPS, animals can express a wide range of behaviours including those unique to this system, such as scratching against shrubs. In other systems, such as confinement or extensive systems without trees, they cannot perform these behaviours.

The avoidance distance average (1.6, 1.2, and $1.3 \mathrm{~m}$ for ISPS 1, 2, and 3, respectively) show a good human-animal relationship, reflected in the final score $(94.97,96.58$, and 98.18). The handling within the ISPS involves constant contact between humans and animals, since the fences are modified daily, so the animals grow accustomed to seeing humans. This may represent an opportunity for animals to be conditioned with positive reinforcement, since the humans often drive the animals from an area with low availability of forage to another area with a better source of feed, making it easy to muster cattle every 12 or $24 \mathrm{~h}$. Comparable results were reported by Ceballos et al. (2016) and Góis et al. (2016), indicating that cattle subjected to a positive and constant contact with humans, when kept under a rotational stocking method, reduced fear toward humans and their reactivity over time.

This good relationship between animals and humans is not only related with the animal docility, but also to occupational safety. Less reactive animals are also less aggressive. It is well known that good human-animal relationship has a positive effect on welfare and productivity (Waiblinger et al., 2006, Hemsworth and Coleman, 2011). There are no reports on the evaluation of avoidance distance in this type of system; however, assessing human-animal relationship in other systems has proven reliable.

Although throughout the past 20 years the proclamation of sentience has increased, paradoxically, we do not yet understand the emotional experiences of animals; hence, the term "animal emotions" is often considered unscientific and anthropocentric (Boissy et al., 2007). However, in recent years, several authors have compiled scientific evidence on the importance of emotions in the quality of life and AW. In this study, ISPS3 showed a good result (71) and ISPS1 (83) and ISPS2 (84) showed excellent results, supporting the hypothesis that in ISPS animals have more positive than negative emotional experiences, possibly because they have sufficient resources and can express different individual and social behaviours. It is known that social behaviours improve resilience (Špinka, 2012). Several features of the ISPS explain the emotional status expressed by animals; it could be said that ISPS offer natural environmental enrichment; conversely, rotational handling exerts a potentially positive anticipation, as described by Boissy et al. (2007).

\section{Conclusions}

Despite the differences in diversity of plants, size of paddocks, and grazing period among the three ISPSs tested, all of them provide cattle with sufficient resources and a diverse environment, ensuring a good state of welfare to them. However, pain and other poor welfare during castration, dehorning and hot-iron branding are still a problem. The first two could be reduced using anaesthesia and analgesia and hot-iron branding could be replaced by less painful marking methods. Intensive silvopastoral systems are beneficial to cattle welfare, good for livestock farmers, and of value for sustainable cattle production in many parts of the world.

\section{Acknowledgments}

We would like to thank the owners and staff of El Chaco, Lucerna, and Altagracia farms for their help and kind reception, allowing the data collection, and Maria Mercedes Murgueitio for her management and logistical support. We are also grateful to "Sostenibilidad Universidad de Antioquia", doctoral training program "Francisco José de Caldas" COLCIENCIAS, and CIPAV foundation for the financial support. Finally, we express our gratitude to Professors Donald Broom and Neville Gregory for their comments and writing revision that greatly improved the manuscript.

\section{References}

Bacab-Pérez, H. M. and Solorio-Sánchez, F. J. 2011. Oferta y consumo de forraje y producción de leche en ganado de doble propósito manejado en sistemas silvopastoriles en Tepalcatepec, Michoacán. Tropical and Subtropical Agroecosystems 13:271-278.

Barros-Rodríguez, M.; Solorio-Sánchez, J.; Ku-Vera, J.; Ayala-Burgos, A.; Sandoval-Castro, C. and Solís-Pérez, G. 2012. Productive performance and urinary excretion of mimosine metabolites by hair sheep grazing in a silvopastoral system with high densities of Leucaena leucocephala. Tropical Animal Health and Production 44:1873-1878.

Blackshaw, J. and Blackshaw, A. 1994. Heat stress in cattle and the effect of shade on production and behaviour: a review. Australian Journal of Experimental Agriculture 34:285-295.

Boissy, A.; Manteuffel, G.; Jensen, M. B.; Moe, R. O.; Spruijt, B.; Keeling, L. J.; Winckler, C.; Forkman, B.; Dimitrov, I.; Langbein, J.; Bakken, M.; Veissier, I. and Aubert, A. 2007. Assessment of positive emotions in animals to improve their welfare. Physiology Behaviour 92:375-397.

Brew, M. N.; Myer, R. O.; Hersom, M. J.; Carter, J. N.; Elzo, M. A.; Hansen, G. R. and Riley, D. G. 2011. Water intake and factors affecting water intake of growing beef cattle. Livestock Science 140:297-300.

Broom, D. M. 1986. Indicators of poor welfare. The British Veterinary Journal 142:524-526. 
Broom, D. M. 2010. Animal welfare: an aspect of care, sustainability, and food quality required by the public. Journal of Veterinary Medical Education 37:83-88.

Broom, D. M. 2011. A history of animal welfare science. Acta Biotheoretica 59:121-137.

Broom, D. M.; Galindo, F.A. and Murgueitio, E. 2013. Sustainable, efficient livestock production with high biodiversity and good welfare for animals. Proceedings of the Royal Society B 280:2013-2025.

Busato, A.; Trachsel, P. and Blum, J. W. 2000. Frequency of traumatic cow injuries in relation to housing systems in Swiss organic dairy herds. Journal of Veterinary Medicine Series A-Physiology Pathology Clinical Medicine 47:221-229.

Ceballos, M. C.; Cuartas, C. A.; Naranjo, J. F.; Rivera, J. E.; Arenas, F.; Murgueitio, E. and Tarazona, A. M. 2011. Efecto de la temperatura y la humedad ambiental sobre el comportamiento de consumo en sistemas silvopastoriles intensivos y posibles implicaciones en el confort térmico. Revista Colombiana de Ciencias Pecuarias 24:368.

Ceballos, M. C.; Góis, K. C. R.; Sant'Anna, A. C. and Paranhos da Costa, M. J. R. 2016. Frequent handling of grazing beef cattle maintained under the rotational stocking method improves temperament over time. Animal Production Science. doi: http:// dx.doi.org/10.1071/AN16025

Cook, N. B. and Nordlund, K. V. 2009. The influence of the environment on dairy cow behaviour, claw health and herd lameness dynamics. Veterinary Journal 179:360-369.

Cozzi, G.; Ricci, R.; Dorigo, M. and Zanet, D. 2010. Growth performance, cleanliness and lameness of finishing Charolais bulls housed in littered pens of different design. Italian Journal of Animal Science 4:251-256.

CSIRO - Commonwealth Scientific and Industrial Research Organisation. 2007. Nutrient requirements of domesticated ruminants. CSIRO Publishing, Australia.

Dalmau, A.; Temple, D.; Rodriguez, P.; Llonch, P. and Velarde, A. 2009. Application of the Welfare Quality ${ }^{\circledR}$ protocol at pig slaughterhouses. Animal Welfare 18:497-505.

Dippel, S.; Dolezal, M.; Brenninkmeyer, C.; Brinkmann, J.; March, S.; Knierim, U. and Winckler, C. 2009. Risk factors for lameness in cubicle housed Austrian Simmental dairy cows. Preventive Veterinary Medicine 90:102-112.

Dobson, H.; Tebble, J. E.; Smith, R. F. and Ward, W. R. 2001. Is stress really all that important? Theriogenology 55:65-73.

Fisher, A. D.; Crowe, M. A.; O’Kiely, P. and Enright, W. J. 1997. Growth, behaviour, adrenal and immune responses of finishing beef heifers housed on slatted floors at 1.5, 2.0, 2.5 or $3.0 \mathrm{~m}^{2}$ space allowance. Livestock Production Science 51:245-254.

Forkman, B. and Keeling, L. (Eds). 2009. Assessment of animal welfare measures for dairy cattle, beef bulls and veal calves. Welfare Quality Reports No. 11. Cardiff University, Cardiff, United Kingdom.

Gaughan, J.; Lacetera, N.; Valtorta, S. E.; Khalifa, H. H.; Hahn, L. and Mader, T. 2009. Response of domestic animals to climate challenges. p.131-170. In: Biometeorology for adaptation to climate variability and change. Burton, K. L. and McGregor, I., eds. Springer, Dordrecht, Netherlands.

Giraldo, C.; Escobar, F.; Chará, J. D. and Calle, Z. 2011. The adoption of silvopastoral systems promotes the recovery of ecological processes regulated by dung beetles in the Colombian Andes. Insect Conservation and Diversity 4:115-122.

Góis, K. C. R.; Ceballos, M. C.; Sant'Anna, A. C. and Paranhos da Costa, M. J. R. 2016. Using an observer rating method to assess the effects of rotational stocking method on beef cattle temperament over time. Revista Brasileira de Zootecnia 45:501-508.
Haydock, K. P. and Shaw, N. H. 1975. The comparative yield method for estimating dry matter yield of pasture. Australian Journal of Experimental Agriculture and Animal Husbandry 15:663-667.

Hemsworth, P. H. and Coleman, G. J. 2011. Human-livestock interactions: The stockperson and the productivity of intensively farmed animals. 2nd ed. CABI International, Wallingford, UK.

Holdridge, L. 1987. Ecología basada en zonas de vida. Instituto Interamericano de Cooperación para la Agricultura, San José, Costa Rica.

Kirchner, M. K.; Westerath, H. S.; Knierim, U.; Tessitore, E.; Cozzi, G.; Pfeiffer, C. and Winckler, C. 2014. Application of the Welfare Quality ${ }^{\circledR}$ assessment system on European beef bull farms. Animal 8:827-835.

Leach, K. A.; Knierim, U. and Whay, H. R. 2009. Cleanliness scoring for dairy and beef cattle and veal calves. p.22-30. In: Welfare Quality ${ }^{\circledR}$ Reports 11. Assessment of animal welfare measures for dairy cattle, beef bulls and veal calves. Forkman, B.; Keeling, L., eds. Cardiff University, Cardiff, United Kingdom.

Mancera, A. K. and Galindo, F. 2011. Evaluation of some sustainability indicators in extensive bovine stockbreeding systems in the state of Veracruz. In: VI Reunión Nacional de Innovación Forestal 31, León Guanajauato, México.

Manteca, X.; Villalba, J. J.; Atwood, S. B.; Dziba, L. and Provenza, F. D. 2008. Is dietary choice important to animal welfare? Journal of Veterinary Behavior: Clinical Applications and Research 3:229-239.

Mota, D.; Ceballos, M. C.; Orihuela, A.; Corredor, M. C.; Pérez, E.; Ramírez, R.; César, D. 2016. Prácticas dolorosas en animales de granja. p.137-154. In: Bienestar Animal: una visión global en Iberoamérica. 3ra ed. Mota-Rojas, D.; Velarde, A.; Huertas, S. and Cajiao, M. N., eds. Elsevier España S.L.U., Barcelona, España.

Mott, G. O. 1960. Grazing pressure and the measurement of pasture production. p.606-611. In: Proceedings of the 8th International Grassland Conference. Alden Press, Oxford.

Munksgaard, L. and Simonsen, H. B. 1996. Behavioral and pituitary adrenal-axis responses of dairy cows to social isolation and deprivation of lying down. Journal of Animal Science 74:769-778.

Murgueitio, E.; Calle, Z.; Uribe, F.; Calle, A. and Solorio, B. 2011. Native trees and shrubs for the productive rehabilitation of tropical cattle ranching lands. Forest Ecology and Management 261:1654-1663.

Paranhos da Costa, M. J. R. and Silva, E. V. 2007. Aspectos básicos do comportamento social de bovinos. Revistra Brasileira de Reprodução Animal 31:172-176.

Rousing, T. and Wemelsfelder, F. 2006. Qualitative assessment of social behaviour of dairy cows housed in loose housing systems. Applied Animal Behaviour Science 101:40-53.

Rueda, O. A.; Cuartas, C.A.; Naranjo, J. F.; Córdoba, C. P.; Murgueitio, E. and Anzola, H. 2011. Comportamiento de variables climáticas durante estaciones secas y de lluvia, bajo influencia del ENSO 2009-2010 (El Niño) y 2010-2011 (La Niña) dentro y fuera de sistemas silvopastoriles intensivos en el Caribe seco de Colombia. Revista Colombiana de Ciencias Pecuarias 24:512.

Schulze, H.; Leach, K. A.; Whay, H. R. and Knierim, U. 2009. Scoring of cattle: integument alterations in dairy and beef cattle and veal calves. p.43-50. In: Welfare Quality ${ }^{\circledR}$ Reports 11. Assessment of animal welfare measures for dairy cattle, beef bulls and veal calves. Forkman, B. and Keeling, L., eds. Cardiff University, Cardiff, United Kingdom.

Sousa, L. F.; Maurício, R. M.; Gonçalves, L. C.; Saliba, E. O. S. and Moreira, G. R. 2007. Productivity and nutritional value of Brachiaria brizantha cv. Marandu in a silvopastoral system. Arquivo Brasileiro de Medicina Veterinaria e Zootecnia 59:1029-1037.

Sousa, L. F.; Maurício, R. M.; Moreira, G. R.; Gonçalves, L. C.; Borges, I. and Pereira, L. G. R. 2010. Nutritional evaluation 
of "Braquiarão" grass in association with "Aroeira" trees in a silvopastoral system. Agricultural Systems 79:189-199.

Špinka, M. 2012. Social dimension of emotions and its implication for animal welfare. Applied Animal Behaviour Science 138:170-181.

Steinfeld, H.; Gerber, P.; Wassenaar, T.; Castel, V.; Rosales, M. and De Haan, C. 2006. Livestock's long shadow: Environmental issues and options. Food and Agriculture Organization of the United Nations. FAO, Rome, Italy.

Stookey, J. M. and Gonyou, H. W. 1994. The effects of regrouping on behavioral and production parameters in finishing swine. Journal of Animal Science 72:2804-2811.

Tarazona, A. M.; Ceballos, M. C.; Cuartas, C. A.; Naranjo, J. F.; Murgueitio, E. and Barahona, R. 2013. The relationship between nutritional status and bovine welfare associated to adoption of intensive silvopastoral systems in tropical conditions. In: FAO. Enhancing animal welfare and farmer income through strategic animal feeding - Some case studies. Harinder P. S. Makkar, ed. FAO Animal Production and Health Paper No. 175. Rome, Italy.

Temple, D.; Dalmau, A.; de la Torre, J. L. R.; Manteca, X. and Velarde, A. 2011. Application of the Welfare Quality ${ }^{\circledR}$ protocol to assess growing pigs kept under intensive conditions in Spain. Journal of Veterinary Behavior: Clinical Applications and Research 6:138-149.

Waiblinger, S.; Boivin, X.; Pedersen, V.; Tosi, M. V.; Janczak, A. M.; Visser, E. K. and Jones, R. B. 2006. Assessing the human-animal relationship in farmed species: A critical review. Applied Animal Behaviour Science 101:185-242.

Welfare Quality ${ }^{\circledR}$. 2009. Welfare Quality ${ }^{\circledR}$ Assessment Protocol for Cattle. 1st ed. Welfare Quality Consortium, Lelystad, Netherlands.

Wemelsfelder, F.; Hunter, E. A.; Mendl, M. T. and Lawrence, A. B 2000. The spontaneous qualitative assessment of behavioural expressions in pigs: first explorations of a novel methodology for integrative animal welfare measurement. Applied Animal Behaviour Science 67:193-215. 